\title{
Predição da Composição Física e Química da Carcaça a Partir da Composição das Diferentes Regiões Corporais de Bezerros Machos de Origem Leiteira até os 110 Dias de Vida ${ }^{1}$
}

\author{
Paulo Afonso Carvalho², Luis Maria Bonnecarrère Sanchez ${ }^{3}$ Cleber Cassol Pires $^{3}$, \\ Julio Viégas ${ }^{3}$, João Pedro Velho ${ }^{4}$, Wagner Paris ${ }^{5}$
}

\begin{abstract}
RESUMO - O presente estudo foi desenvolvido com o objetivo de desenvolver equações de estimativa da composição física e química da carcaça de bezerros de origem leiteira, no início da vida produtiva. Foram usados 18 bezerros da raça Holandês, machos, não castrados, pesando entre 30 e $100 \mathrm{~kg}$. Seis animais foram abatidos no início do experimento (ao nascimento), seis aos 50 dias e seis aos 110 dias de idade. Foi realizada a divisão da carcaça em dianteiro, costilhar, traseiro e secção 9a-11ㅡㅡ costelas e procedida a separação física total de todos os constituintes da carcaça. Foi determinada a composição física e química por um método direto e ajustadas equações de predição para estimar a composição física e química da carcaça, por um método indireto. Os dados de composição física da secção 9ā-11ā costelas também foram tabulados nas equações propostas por Hankins e Howe, para testar a utilização das mesmas em animais jovens e imaturos. O traseiro foi a região que melhor representou a composição física de osso, músculo e gordura, assim como a composição química de água e cinzas da carcaça. No entanto, a composição energética e protéica foi mais bem representada pela composição energética e protéica do dianteiro. A composição física e química do corte da 9a-11aㅡ costelas não foi um bom estimador da composição física e química da carcaça de animais imaturos fisiologicamente ou extremamente jovens.
\end{abstract}

Palavras-chave: bovinos, corte da costela, equações de estimativa

\section{Prediction of the Physical and Chemical Composition of the Carcass starting from the Composition of the Corporal Parts of Dairy Male Calves to 110 Days of Age}

ABSTRACT- The study was carried out to develop predictions equations of the physical and chemical composition of dairy calves carcass. Eighteen Holstein bulls calves weighing between 30 and $100 \mathrm{~kg}$ were used. Groups of six animals were slaughtered at birth, 50 and 110 days of age. The carcass was divided in forequarter, rib, hindquarter and 9-1 ${ }^{\text {th }}$ rib section and dissection of each part was carried out. The physical and chemical composition was determined by a direct method and prediction equations were adjusted to estimate the physical and chemical composition of the carcass by an indirect method. The data of physical composition of the 9-11 th rib section were used to test the equation proposed by Hankins and Howe in young and immature animals. The physical composition of bone, muscle and fat, as well the chemical composition of water and ashes of the carcass were best represented by the hindquarter. However, the energy and protein chemical composition were represented better by the energy and protein composition the forequarter. The physical and chemical composition of the $9-11^{\text {th }}$ rib cut was not a good estimate of young calves carcass.

Key Words: cattle, prediction equations, rib cut

\section{Introdução}

Na produção de bovinos para corte a performance e determinação da composição corporal dos animais é de extrema importância, frente à necessidade de obtenção de carcaças com elevada proporção de músculo e adequada deposição de gordura, obtidas de maneira eficiente e de acordo com as exigências do mercado consumidor.
O aumento de peso é a principal característica que define a resposta produtiva animal, estando sempre relacionado com o estado de desenvolvimento corporal e com a conversão de alimentos em produto (Di Marco, 1994). O ganho de peso corporal está associado a diferentes padrões de crescimento dos tecidos corporais, com taxas de crescimento inerentes a distintas fases da vida do animal (Almeida et al., 2000).

\footnotetext{
1 Parte da Dissertação apresentada à Universidade Federal de Santa Maria (UFSM), pelo primeiro autor como um dos requisitos para obtenção do Título de Mestre em Zootecnia.

2 Zootecnista, M.Sc. Doutorando pela Universidade Federal de Lavras (UFLA). Bolsista CNPq. Rua Progresso, 41/801. Lavras, MG. 37200.000. Autor para correspondência. pac@ufla.br

3 Professor do Deptartamento de Zootecnia da UFSM, RS.

${ }^{4}$ Acadêmico de Zootecnia (UFSM) - Bolsista de iniciação científica CNPq.

${ }^{5}$ Zootecnista, Mestrando em Zootecnia pela Universidade Estadual de Maringá (UEM), PR.
} 
Na fase inicial da vida produtiva, as características metabólicas e fisiológicas determinam maior taxa de retenção de proteínas, conferindo a animais jovens uma composição corporal diferente de animais maduros ou adultos, onde ocorre maior retenção de gorduras (Berg \& Butterfield, 1976). Outro fator que deve ser considerado é a elevada proporção de tecido ósseo em animais muito jovens.

A proporção de ossos na carcaça diminui lentamente, à medida que o peso do animal aumenta, constituindo o tecido sujeito à menor variação percentual. Os músculos representam alta porcentagem do peso total ao nascimento, aumentando ligeiramente com o peso corporal, mas começando a decrescer proporcionalmente à medida que se inicia a fase de deposição de gordura (Signoretti et al., 1999).

Os componentes químicos da carcaça (água, proteína, gordura e minerais) variam durante o crescimento, de forma paralela à composição física (tecido muscular, ósseo e adiposo) e ambos são influenciados por fatores como idade, peso, raça, sexo e nível nutricional, refletindo nos custos de produção e qualidade do produto final obtido.

De acordo com Véras (2000) os métodos utilizados para estimar a composição corporal e, ou, da carcaça são classificados em diretos ou indiretos. Os métodos diretos consistem na separação total e dissecação de todas as partes do corpo do animal e subsequente determinação dos constituintes físicos e químicos, sendo estes mais precisos. Entretanto, além de laboriosos, os métodos diretos não permitem a comercialização das carcaças, demasiadamente manipuladas. Já os métodos indiretos envolvem a estimativa da composição do corpo ou da carcaça, a partir de parâmetros mais facilmente obtidos. Assim, vários métodos indiretos têm sido desenvolvidos para estimar a composição do corpo e da carcaça dos animais.

Embora reconheçam a precisão dos métodos diretos, Alleoni et al. (1997) e Carvalho (1998) destacam a necessidade e importância de se realizarem mais estudos, visando o ajuste de equações para o estabelecimento dos métodos indiretos, com adequada confiabilidade, facilitando os estudos de determinação de composição corporal e exigências nutricionais em diferentes ambientes e categorias animais.

A determinação da composição da carcaça por intermédio de um método indireto já é utilizada há bastante tempo, conforme demonstrado por Hankins \& Howe (1946), os quais definiram uma metodologia para a obtenção de uma amostra compreendendo a 9aㅗ $10^{\mathrm{a}}$ e $11^{\mathrm{a}} \underline{\mathrm{a}}$ costelas (Secção $\mathrm{HH}$ ) e ajustaram equações para estimar a composição física e química da carcaça a partir da composição deste corte, realizado nas carcaças de bovinos das raças Aberdeem Angus, Brahman, Hereford e Shorthorn com idade variando de 9 a 35 meses e peso vivo ao abate de 250 a $640 \mathrm{~kg}$. Desde então, tais equações têm sido utilizadas com freqüência, como nos estudos conduzidos por Almeida (1995); Fontes (1995); Peron et al. (1995); Alleoni et al. (1997); Backes (1998); Ferreira et al. (1999); Ferreira \& Valadares Filho (1999); Rocha \& Fontes (1999) e Véras (2000).

Da mesma maneira que Hankins \& Howe (1946), os referidos autores trabalharam com animais experimentais apresentando um peso vivo ao abate compreendido entre 250 e $550 \mathrm{~kg}$, ou seja, animais com maturidade fisiológica bastante desenvolvida ou adulta. No entanto, para bovinos mais jovens, com menores pesos vivo e imaturos fisiologicamente, os resultados não são bem conhecidos, visto que essas equações foram ajustadas para uma outra categoria animal.

De acordo com Rocha \& Fontes (1999), os pesquisadores nacionais, na maioria das vezes, têm se dedicado prioritariamente ao estudo de ganho de peso, composição corporal e exigências nutricionais de animais provenientes de rebanhos especializados para corte. Além disso, os animais são abatidos com pesos vivos entre 350 e $550 \mathrm{~kg}$. Existe, portanto, no Brasil, carência de informações de animais de origem leiteira, abatidos a menores pesos.

Nesse sentido, é importante identificar, em condições nacionais, qual parte da carcaça melhor representa física e quimicamente a carcaça de bezerros de origem leiteira na fase inicial da vida produtiva para poder determinar com maior facilidade e precisão a composição física e química da carcaça e do corpo e, conseqüentemente, as exigências nutricionais para essa categoria de animais.

\section{Material e Métodos}

O presente estudo foi conduzido no Setor de Nutrição Animal do Departamento de Zootecnia da Universidade Federal de Santa Maria, RS, no período compreendido entre outubro de 1999 e março de 2001. Foram utilizados 18 bezerros da raça Holandês, machos, não castrados, dos quais seis foram abatidos ao nascimento, seis aos 50 dias e seis aos 110 dias de vida. Antecedendo o momento do abate os animais foram pesados em balança mecânica e, então, sacri- 
ficados por secção da veia jugular. Foi realizada a esfola para a retirada do couro e procedida a abertura do osso esterno do peito bem como da cavidade abdominal, para a retirada dos órgãos e vísceras.

Logo após o abate, foram separadas do corpo e pesadas as patas e a cabeça e efetuado um corte longitudinal dividindo as carcaças ao meio. Nesse momento foram pesados todos os constituintes corporais, triturados e congelados para posteriores análises de constituição. O peso corporal vazio foi obtido diretamente pelo somatório dos pesos de patas, cabeça, couro, sangue, órgãos, vísceras vazias, gordura interna e carcaça. O peso corporal vazio também foi obtido indiretamente por regressão, ajustando-se equações de predição do peso de corpo vazio em função do peso vivo ao abate e peso de carcaça quente, assim como também se ajustou equações de predição do peso de carcaça quente, em função do peso vivo ao abate dos animais experimentais.

Logo em seguida aos procedimentos do abate e amostragem dos constituintes corporais, as carcaças quentes foram pesadas e resfriadas em câmara frigorífica a uma temperatura de $2^{\circ} \mathrm{C}$ por 24 horas. Decorrido esse período, foram realizadas avaliações quantitativas nas carcaças, de acordo com metodologias e procedimentos descritos por Lauzer (1977), Müller (1987) e Perobelli (1993).

Depois de efetuadas as medições na carcaça fria, realizou-se o seccionamento em diferentes regiões de constituição:

- Dianteiro (Diant): Por corte transversal entre a 8a-9 vértebra torácica.

- Costilhar (Cost): Por corte longitudinal rente ao músculo Longissimus dorsi.

- Traseiro (Tras): Por corte transversal entre a 11 a -12 a vértebra torácica, ficando com as duas últimas costelas.

- Secção 9â-11a costelas (Seç̧ão 9-11): Porção compreendida entre a 9a-11 $\underline{a}$ costelas com vértebras, secionada longitudinalmente a altura de $61 \%$ do comprimento da costela, a partir da vértebra torácica correspondente, conforme metodologia descrita por Hankins \& Howe (1946).

A composição tecidual foi determinada de maneira direta, pela separação física total dos tecidos de constituição nas diferentes regiões da carcaça, sendo analisados os percentuais de osso, músculo e gordura no dianteiro, costilhar, traseiro e secção 9 a-1 $11^{\mathrm{a}}$ costelas. Os dados obtidos na secção da costela foram considerados na composição do costilhar, adicionando-se os valores ao mesmo. O somatório da composição nas diferentes regiões permitiu a obtenção dos dados de carcaça. As medições foram realizadas na $1 \frac{1}{2}$ carcaça esquerda e depois extrapolado para a carcaça inteira.

Para determinação indireta da composição física tecidual da carcaça foram realizadas análises de regressão para ajustar equações de predição da composição de osso, músculo e gordura da carcaça em função da porcentagem destes tecidos no dianteiro, costilhar, traseiro e secção $9 \underline{a}-11$ a costelas.

Os diferentes tecidos de constituição das regiões da carcaça foram triturados separadamente. Nesse momento, foram obtidas amostras de tecido mole (músculo + gordura) do dianteiro (DIAM), costilhar (COSM), traseiro (TRAM) e secção $9 \underline{a}-11$ a costelas (SECM), bem como de osso do dianteiro (DIAO), costilhar (COSO), traseiro (TRAO) e secção $9 \underline{a}-11^{\underline{a}}$ costelas (SECO), assim como amostras compostas de tecido mole e de osso representativo da carcaça inteira para cada animal experimental.

As amostras de tecido mole, assim como as de osso, foram pré-desengorduradas com éter de petróleo, conforme metodologia descrita por Kock \& Preston (1979). As amostras foram finamente moídas e procedidas as análises laboratoriais. O teor de gordura total da amostra foi obtido somando-se a gordura removida no pré-desengorduramento com o extrato etéreo residual.

As composições de matéria seca, nitrogênio total, extrato etéreo e cinzas foram obtidas diretamente através de análises proximais realizadas nas diferentes partes e na carcaça como um todo, segundo metodologias descritas por Silva (1990). Para determinação indireta da composição química da carcaça foram realizadas análises de regressão para ajustar equações de predição da composição de água, extrato etéreo, proteína bruta e cinzas da carcaça em função da porcentagem destes constituintes no dianteiro, costilhar, traseiro e secção $9 \underline{a}-11 \underline{a}$ costelas.

O delineamento experimental foi inteiramente casualisado, constando de três tratamentos (idades de abate) e seis repetições por tratamento, sendo a unidade experimental representada por um animal. As análises estatísticas foram realizadas por intermédio do programa computacional SAS (1996). 


\section{Resultados e Discussão}

Na Tabela 1, encontram-se as equações obtidas para estimar o peso de corpo vazio (PCVZ) a partir do peso vivo ao abate (PVA) e do peso de carcaça (PCARC), bem como para estimar o PCARC a partir do PVA. As mesmas foram ajustadas utilizando-se os dados de todos os animais experimentais, cujos PVA individuais variaram de 30 a $100 \mathrm{~kg}$ com correspondentes PCVZ variando de 27,57 a 74,27 kg.

Todas as equações apresentaram ajuste linear altamente significativo $(\mathrm{P}<0,01)$. Os elevados coeficientes de determinação das equações sugerem que o PCVZ pode ser previsto com segurança, a partir do PVA e PCARC, assim como também o PCARC pode ser estimado a partir do PVA, para bezerros da raça Holandês, machos não castrados e dentro da faixa de peso referida no presente estudo.

Lana et al. (1992) ajustaram equações lineares para estimar o PCVZ com base no PCARC e no PVA de bovinos de diversos grupos genéticos e suas cruzas, com idade média de 24 meses e pesando $330 \mathrm{~kg}$. A estimativa do PCVZ a partir do PCARC apresentou $r^{2}$ de 98\%. Estrada et al. (1993) ajustaram equações de predição para bovinos adultos, taurinos, zebuínos e mestiços, obtendo $r^{2}$ de $97 \%$ para a equação que estima o PCVZ a partir do PVA e de $96 \%$ para a equação que estima o PCARC a partir do PVA. Véras (2000) obteve $\mathrm{r}^{2}$ de $94 \%$ para a equação que prediz o PCVZ a partir do PVA em zebuínos, abatidos com pesos variando de 300 a $450 \mathrm{~kg}$. Todavia, Rocha et al. (1999) obtiveram, com novilhos da raça Holandês, $\mathrm{r}^{2}$ de $99 \%$ na equação ajustada para estimar o PCVZ a partir do PVA.

Na Tabela 2, encontram-se as equações ajusta- das para estimar a composição física da carcaça, a partir da composição tecidual das diferentes partes da carcaça.

As equações que melhor se ajustaram ao modelo $(\mathrm{P}<0,01)$ foram as equações que estimam a proporção de osso, músculo e gordura da carcaça, a partir da proporção de osso, músculo e gordura do traseiro.

As equações para estimar a composição tecidual da carcaça a partir da composição física da secção 9ํ-11a costelas não apresentaram bom ajuste ao modelo linear adotado. As equações relativas a osso e músculo não foram significativas $(\mathrm{P}>0,05) \mathrm{com}$ coeficientes de determinação de 15,7 \% para osso e $17,4 \%$ para músculo. A equação que estima a proporção de gordura na carcaça em função da proporção deste tecido na secção 9 ${ }^{\mathrm{a}}-11^{\mathrm{a}}$ - costelas ajustou-se significativamente $(\mathrm{P}<0,01)$, entretanto, o $\mathrm{r}^{2}$ obtido pela equação indica que apenas $69,37 \%$ da variação de gordura na carcaça pode ser explicado pela variação de gordura na secção 9â-11aㅡ costelas.

Quando os dados de composição física da secção 9a $-11^{\mathrm{a}}$ costelas dos bezerros experimentais foram tabulados nas equações propostas por Hankins \& Howe (1946) foram obtidos valores estimados de 23,20 \% de osso, 65,82 \% de músculo e 7,68 \% de gordura na carcaça. Todavia, os reais valores observados no experimento, para essas características foram de 27,94 \% de osso, 65,85 \% de músculo e 5,87 $\%$ de gordura na carcaça. As equações de Hankins \& Howe (1946) subestimaram a proporção de osso (23,20 vs $27,94 \%$ ) e superestimaram a proporção de gordura (7,68 vs $5,87 \%)$ na carcaça dos bezerros. Tal fato indica que quando se colocam dados de animais jovens nas equações $\mathrm{HH}$, a confiabilidade do resultado é reduzida. Portanto, tais equações devem

Tabela 1 - Equações de regressão, coeficientes de determinação $\left(r^{2}\right)$ e níveis de significância $(P>F)$ para a predição do peso de corpo vazio (PCVZ) em função do peso vivo ao abate (PVA) e do peso de carcaça (PCARC), em bezerros até os 110 dias de idade

Table 1 - Regression equations, determination coefficients $\left(r^{2}\right)$ and significance levels (P>F) for empty body weight (EBW) prediction in according to the slaughter live weight (SLW) and carcass weight (CW) of dairy calves to 110 days of age

\begin{tabular}{lcc}
\hline $\begin{array}{l}\text { Equação de regressão } \\
\text { Regression Equation }\end{array}$ & $\mathrm{r}{ }^{2}$ & $\mathrm{P}>\mathrm{F}$ \\
\hline $\mathrm{PCVZ}=7,557670+0,667101$ PVA & 98,41 & 0,0001 \\
$E B W=7,557670+0,667101$ SLW & 97,74 & 0,0001 \\
$\mathrm{PCVZ}=1,120646+1,513948$ PCARC & & \\
$E B W=1,120646+1,513948 C W$ & 98,90 & 0,0001 \\
PCVZ $=4,666494+0,406099$ PVA $+0,604045$ PCARC & & 0,0001 \\
$E B W=4,666494+0,406099 S L W+0,604045 C W$ & 96,81 & \\
$P C A R C=4,786361+0,432091$ PVA & & \\
$C W=4,786361+0,432091 S L W$ & & \\
\hline
\end{tabular}


ser utilizadas apenas para animais maduros fisiologicamente.

Constam na Tabela 3 as equações ajustadas para estimar a proporção de água, extrato etéreo, proteína bruta e cinzas na carcaça, em função da composição química proporcional desses elementos nas diferentes partes da carcaça.

As equações para estimar a proporção de água e cinzas na carcaça que melhor ajuste apresentaram ao modelo adotado foram aquelas ajustadas em função da quantidade desses constituintes no traseiro, sendo ambas significativas $(\mathrm{P}<0,01)$ e capazes de explicar $78,99 \%$ da variação de água e $85,91 \%$ da variação de cinzas na carcaça dos bezerros.

A equação que estima a concentração de água na carcaça em função da concentração de água na secção 9a-11a costelas apresentou ajuste significativo $(\mathrm{P}<0,01)$ explicando $64,83 \%$ da variação da proporção de água na carcaça. No entanto, a equação ajustada para estimar o percentual de cinzas na carcaça a partir da proporção de cinzas na secção 9믄 $11^{\text {a }}$ costelas foi significativa a $2,41 \%$, mas com coeficiente de determinação de apenas 27,96\%.

Henrique et al. (1999) trabalhando com bovinos inteiros da raça Santa Gertrudis, com 340 a 505 kg de $\mathrm{PV}$, ajustaram equações para estimar o percentual de água corporal a partir da composição de água da secção 9a-11 $\underline{a}$ costelas e obtiveram um coeficiente de determinação de 92,49\%. De maneira semelhante, Alleoni et al. (2000) verificaram correlação significa-

Tabela 2- Equações de regressão, coeficientes de determinação $\left(r^{2}\right)$ e níveis de significância $(P>F)$ para a predição da porcentagem de osso, músculo e gordura da carcaça (CARO, CARM e CARG), em função do percentual de osso, músculo e gordura do dianteiro (DIAO, DIAM e DIAG), costilhar (COSO, COSM e COSG), traseiro (TRAO, TRAM e TRAG) e secção 9․-11a costelas (SECO, SECM e SECG)

Table 2 - Regression equations, determination coefficients $\left(r^{2}\right)$ and significance levels ( $\left.P>F\right)$ for bone, muscle and fat carcass percentage prediction (CARB, CARM and CARF), according to the bone, muscle and fat in forequarter percentage (FORB, FORM and FORF), rib (RIBB, RIBM and RIBF), hindquarter (HINB, HINM and HINF) and 9-11 th rib section (SECB, SECM and SECF)

Equação de regressão

$\mathrm{r}^{2} \quad \mathrm{P}>\mathrm{F}$

Regression Equation

Osso

Boné

$\mathrm{CARO}=9,449906+0,618359 *$ DIAO

55,88

0,0004

$C A R B=9,449906+0,618359 *$ FORB

$\mathrm{CARO}=15,944005+0,465584 * \mathrm{COSO}$

12,67

0,1471

$C A R B=15,944005+0,465584 * R I B B$

$\mathrm{CARO}=11,018786+0,620653 * \mathrm{TRAO}$

82,83

0,0001

$C A R B=11,018786+0,620653 *$ HINB

$\mathrm{CARO}=16,550140+0,376080 * \mathrm{SECO}$

15,27

0,1089

$C A R B=16,550140+0,376080 *$ SECB

Músculo

CARM $=26,961269+0,592215 *$ DIAM

Muscle

CARM $=26,961269+0,592215 *$ FORM

CARM $=36,247284+0,444252 *$ COSM

$C A R M=36,247284+0,444252 * R I B M$

$\mathrm{CARM}=26,771347+0,588944 *$ TRAM

CARM $=26,771347+0,588944 *$ HINM

CARM $=47,599255+0,281678 *$ SECM

$C A R M=47,599255+0,281678 * S E C M$

53,99

0,0005

18,01

0,0792

76,22

0,0001

17,40

0,0850

Gordura

CARG $=2,592200+0,738667 *$ DIAG

Fat

CARF $=2,592200+0,738667 * F O R F$

CARG $=0,630555+0,688806 *$ COSG

0,0001

$C A R F=0,630555+0,688806 * R I B F$

CARG $=-0,264895+0,960565 *$ TRAG

0,0010

CARF $=-0,264895+0,960565 *$ HINF

CARG $=3,151137+0,554102 *$ SECG

CARF $=3,151137+0,554102 * S E C F$

86,84

0,0001

68,37

0,0001

R. Bras. Zootec., v.32, n.6, p.1500-1507, 2003 
Tabela 3 - Equações de regressão, coeficientes de determinação $\left(r^{2}\right)$ e níveis de significância (P>F) para a predição da porcentagem de água, extrato etéreo, proteína bruta e cinzas na carcaça (CARAG, CAREE, CARPB e CARCZ), em função da concentração desses constituintes no dianteiro (DIAAG, DIAEE, DIAPB e DIACZ), costilhar (COSAG, COSEE, COSPB e COSCZ), traseiro (TRAAG, TRAEE, TRAPB e TRACZ) e secção 9ㅁ-11aㅡ costelas (SECAG, SECEE, SECPB e SECCZ)

Table 3 - Regression equations, determination coefficients $\left(r^{2}\right)$ and significance levels $(P>F)$ for water, ether extract, crude protein and ash carcass percentage prediction (CARWA, CAREE, CARCP and CARAS), in according to the constituent concentration in the forequarter (FORWA, FOREE, FORCP and FORAS), rib (RIBWA, RIBEE, RIBCP and RIBAS), hindquarter (HINWA, HINEE, HINCP and HINAS) and 9-11 th rib section (SECWA, SECEE, SECCP and SECAS)

Equação de regressão

Regression equations

$\mathrm{r}^{2} \quad \mathrm{P}>\mathrm{F}$

Água

Water

CARAG $=9,984070+0,829474 *$ DIAAG

CARWA $=9,984070+0,829474 *$ FORWA

CARAG $=34,985176+0,456378 *$ COSAG

CARWA $=34,985176+0,456378 *$ RIBWA

CARAG $=17,264602+0,720124 *$ TRAAG

CARWA $=17,264602+0,720124 *$ HINWA

CARAG $=29,049451+0,587154 *$ SECAG

CARWA $=29,049451+0,587154 *$ SECWA

CAREE $=4,880730+0,946604 *$ DIAEE

CAREE $=4,880730+0,946604 *$ FOREE

$\mathrm{CAREE}=8,747403+0,701467 * \mathrm{COSEE}$

CAREE $=8,747403+0,701467 *$ RIBEE

CAREE $=1,858995+0,833478 *$ TRAEE

CAREE $=1,858995+0,833478 *$ HINEE

CAREE $=5,733669+1,048896 *$ SECEE

CAREE $=5,733669+1,048896 *$ SECEE

CARPB $=19,739050+0,611612 *$ DIAPB

CARCP $=19,739050+0,611612 *$ FORCP

$\mathrm{CARPB}=22,351020+0,542245 *$ COSPB

$C A R C P=22,351020+0,542245 *$ RIBCP

$\mathrm{CARPB}=31,183707+0,399922 * \mathrm{TRAPB}$

CARCP $=31,183707+0,399922 *$ HINCP

$\mathrm{CARPB}=32,061333+0,403046 * \mathrm{SECPB}$

$C A R C P=32,061333+0,403046 *$ SECCP

CARCZ $=5,444887+0,630800 *$ DIACZ

CARAS $=5,444887+0,630800 *$ FORAS

CARCZ $=9,072082+0,441339 *$ COSCZ

CARAS $=9,072082+0,441339 *$ RIBAS

CARCZ $=3,923834+0,779355 *$ TRACZ

CARAS $=3,923834+0,779355 *$ HINAS

CARCZ $=6,177654+0,536278 *$ SECCZ

CARAS $=6,177654+0,536278 *$ SECAS

$\begin{array}{ll}64,83 & 0,0001 \\ 41,00 & 0,0042 \\ 78,99 & 0,0001 \\ 60,55 & 0,0001\end{array}$

Extrato etéreo

Ether extract

$\begin{array}{ll}95,09 & 0,0001 \\ 47,21 & 0,0016 \\ 85,05 & 0,0001 \\ 65,12 & 0,0001\end{array}$

Proteína bruta

Crude protein

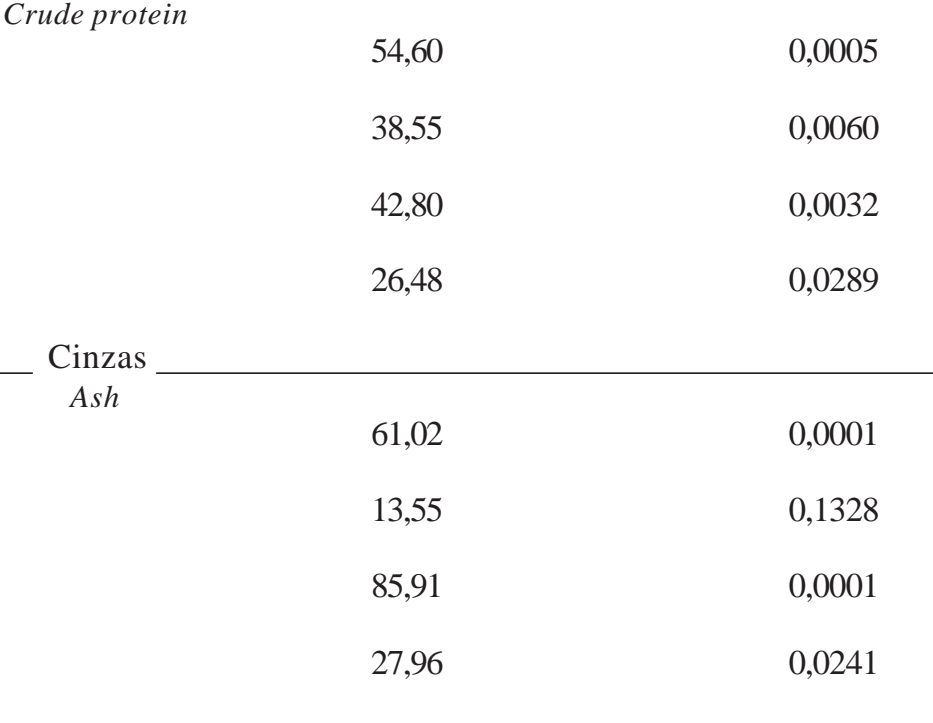

tiva com coeficiente de determinação de 94,8 \% para a equação que estima o percentual de água no corpo de bovinos adultos $3 / 4$ Nelore $1 / 4$ Caracu, em função do percentual de água do corte da 10a costela. Tanto a pesquisa desenvolvida por Henrique et al. (1999) como a por Alleoni et al. (2000), demonstram uma boa precisão na estimativa da composição corporal de água a partir da composição de água de cortes da costela. Entretanto, deve-se considerar que ambas as pesquisas foram desenvolvidas com animais fisiologicamente maduros, bem como, os autores citados estimaram a composição química do corpo e não da 
carcaça, como é o caso dos dados constantes da Tabela 3. Todavia, ressalta-se que a carcaça é o constituinte de maior representatividade no PCVZ.

A equação linear para estimar a composição química da carcaça, que melhor ajuste apresentou $(\mathrm{P}<0,01)$ foi a que estima a composição de extrato etéreo na carcaça a partir da composição de extrato etéreo do dianteiro, com $\mathrm{r}^{2}$ de 95,09\%. Destaca-se que o dianteiro foi a única região da carcaça que ajustou uma equação significativa $\left(r^{2}=52,42 \%\right.$; $\mathrm{P}<0,01)$ para a relação músculo/gordura em função do acréscimo da idade, sendo esta decrescente em função do aumento de idade dos bezerros, indicando uma maior precocidade dessa região da carcaça, acumulando gordura antes das demais regiões da carcaça. A equação que estima o extrato etéreo da carcaça em função do extrato etéreo da secção 9므-11므 costelas ajustou significativamente $(\mathrm{P}<0,01)$, embora apresentando coeficiente de determinação de $65,12 \%$.

Hankins \& Howe (1946) obtiveram, respectivamente, correlações de 0,93 e 0,85 entre a composição química de extrato etéreo da carcaça e da porção comestível e do músculo Longíssimus dorsi na secção 9ㅁ-11a costelas de bovinos das raças Aberdeem Angus, Hereford e Shorthorn com idade variando de 10 a 21 meses e peso vivo ao abate de 250 a $470 \mathrm{~kg}$. As equações ajustadas por Henrique et al. (1999) indicam que a variação do percentual de extrato etéreo da secção $9 \underline{a}$-11a costelas pode explicar até 90,17\% da variação de extrato etéreo no corpo de bovinos maduros avaliados. Já Alleoni et al. (1997) encontraram um coeficiente de determinação de 89\% para a equação linear simples que estima a composição percentual de extrato etéreo corporal em função da concentração deste elemento no corte da $10^{\mathrm{a}}$ costela de bovinos Nelore com peso vivo variando de 245 a $485 \mathrm{~kg}$, enquanto que a equação ajustada por Alleoni et al. (2000), também para animais Nelore, com 21 a 24 meses de idade ao abate, apresenta um coeficiente de determinação de 94,8 \% para a mesma estimativa.

As equações ajustadas para estimar o percentual de proteína bruta na carcaça em função da concentração deste nutriente nas diferentes regiões da carcaça, não apresentaram um bom ajuste ao modelo linear adotado. Os coeficientes de determinação obtidos para as equações ajustadas a partir do dianteiro, costilhar, traseiro e secção 9a-11 1 a costelas foram de 54,60; 38,55; 42,80 e 26,48\%, respectivamente. Tal resultado concorda com a maioria das pesquisas desenvolvidas nesta área de conhecimento, onde as estimativas para as porcentagens de proteína e cinzas apresentam uma baixa precisão.

Os coeficientes de correlação encontrados por Hankins \& Howe (1946) entre as variáveis utilizadas para ajustar equações de estimativa da composição de proteína e cinzas na carcaça, a partir da concentração destes nutrientes na secção 9a-11a costelas foram de 0,84 e 0,46; respectivamente. Entretanto, Alleoni et al. (1997), Henrique et al. (1999) e Alleoni et al. (2000) não encontraram equações capazes de estimar com precisão as porcentagens de proteína e cinzas no corpo dos animais estudados.

\section{Conclusões}

O PCVZ é previsto com segurança, a partir do PVA e PCARC, assim como também o PCARC é estimado a partir do PVA.

O traseiro é a região mais representativa da composição física de osso, músculo e gordura, assim como da composição química de água e cinzas da carcaça de bezerros da raça Holandês até os 110 dias de idade. No entanto, a composição energética e protéica da carcaça é melhor representada pela composição energética e protéica do dianteiro.

A composição física e química do corte da 9a-11 1 a costelas não é um bom estimador da composição física e química da carcaça de animais imaturos fisiologicamente ou extremamente jovens.

Recomenda-se a condução de futuros estudos nessa área, principalmente com animais jovens, o que é ainda bastante deficiente nas condições brasileiras.

\section{Literatura citada}

ALLEONI, G.F.; LEME, P.R.; BOIN, C. et al. Avaliação da composição química e física dos cortes da costela para estimar a composição química corporal de novilhos Nelore. Revista Brasileira de Zootecnia, v.26, n.2, p.382-390, 1997.

ALLEONI, G.F.; LEME, P.R.; BOIN, C. et al. Equações de estimativa da composição química corporal de novilhos Nelore, 3/4 Nelore x 1/4 Canchim e 3/4 Nelore x 1/4 Caracu a partir da composição química do corte da 10 ạ costela. In: REUNIÃO ANUAL DA SOCIEDADE BRASILEIRA DE ZOOTECNIA, 37., 2000, Viçosa, MG. Anais ... Viçosa: Sociedade Brasileira de Zootecnia, 2000. p.436.

ALMEIDA, M.I.V.; FONTES, C.A.A. Deposição de proteína e gordura em componentes corporais de novilhos mestiços Holandês-Gir durante o ganho compensatório. In: REUNIÃO 
ANUAL DA SOCIEDADE BRASILEIRA DE ZOOTECniA, 37., 2000, Viçosa, MG. Anais ... Viçosa: Sociedade Brasileira de Zootecnia, 2000. p.380.

ALMEIDA, S.R.S. Desempenho e exigências líquidas de energia e proteína de novilhos de dois grupos genéticos terminados em confinamento. Santa Maria: Universidade Federal de Santa Maria, 1995. 76p. Dissertação (Mestrado em Zootecnia) - Universidade Federal de Santa Maria, 1995.

BACKES, A.A. Desempenho, composição corporal, exigências nutricionais e validação de diferentes sistemas de arraçoamento para novilhos confinados. Santa Maria: Universidade Federal de Santa Maria, 1998. 160p. Dissertação (Mestrado em Zootecnia) - Universidade Federal de Santa Maria, 1998.

BERG, R.T.; BUTTERFIELD, R.M. New concepts of cattle growth. New York: Sydney University, 1976. 240p.

CARVALHO, S. Desempenho, composição corporal e exigências nutricionais de cordeiros machos inteiros, machos castrados e fêmeas alimentados em confinamento. Santa Maria: Universidade Federal de Santa Maria, 1998. 102p. Dissertação (Mestrado em Zootecnia) - Universidade Federal de Santa Maria, 1998.

DI MARCO, O.N. Crescimiento y respuesta animal. Balcarce: Associación Argentina de Producción Animal, 1994. 129p.

ESTRADA, L.H.C.; FONTES, C.A.A.; MARTINS, M.R. et al. Predição do peso corporal vazio, peso da carcaça e cortes comerciais, com base ao peso vivo de bovinos de três grupos genéticos. In: REUNIÃO ANUAL DA SOCIEDADE BRASILEIRA DE ZOOTECNIA, 30., 1993. Rio de Janeiro. Anais... Rio de Janeiro: Sociedade Brasileira de Zootecnia, 1993. p.475.

FERREIRA, M.A.; VALADARES FILHO, S.C. Composição química corporal de bovinos F1 Simental x Nelore, não castrados, predita através de método indireto. In: REUNIÃO ANUAL DA SOCIEDADE BRASILEIRA DE ZOOTECNIA, 36., 1999, Porto Alegre. Anais ... Porto Alegre: Sociedade Brasileira de Zootecnia, 1999. p.348.

FERREIRA, M.A.; VALADARES FILHO, S.C.; COELHO DA SILVA, J.F. et al. Composição corporal e exigências líquidas de proteína e energia para ganho de peso de bovinos F1 Simental x Nelore. Revista Brasileira de Zootecnia, v.28, n.2, p.352-360, 1999.

FONTES, C.A.A. Composição corporal, exigências líquidas de nutrientes para ganho de peso e desempenho produtivo de animais zebuínos e mestiços europeu-zebú - Resultados experimentais. In: SIMPÓSIO INTERNACIONAL SOBRE EXIGÊNCIAS NUTRICIONAIS DE RUMINANTES, 1995, Viçosa, MG. Anais ... Viçosa: Universidade Federal de Viçosa, 1995. p.419-456.

HANKINS, O.G.; HOWE, P.E. Estimation of the composition of beef carcasses and cuts. Washington, USDA, p.1-20, 1946. (Technical bulletin-USDA, 1946)

HENRIQUE, W.; LEME, P.R.; LANNA, D.P.D. et al. Equações para a estimativa da composição química corporal de tourinhos Santa Gertrudis a partir do corte da 9-10-11a costelas. In: REUNIÃO ANUAL DA SOCIEDADE BRASILEIRA DE ZOOTECnIA, 36., 1999, Porto Alegre. Anais ... Porto Alegre: Sociedade Brasileira de Zootecnia, 1999. p.352.
KOCK, S.W.; PRESTON, R.L. Estimation of bovine carcass composition by the urea diluition techinique. Journal of Animal Science, v.48, n.2, p.319, 1979.

LANA, R.P.; FONTES, C.A.A.; MORAIS, C.A.C. et al. Predição do peso de corpo vazio com base no peso de carcaça e peso vivo, em bovinos. In: In: REUNIÃO ANUAL DA SOCIEDADE BRASILEIRA DE ZOOTECNIA, 29., 1992, Lavras. Anais... Lavras: Sociedade Brasileira de Zootecnia, 1992. p.165.

LAUZER, J.J. Fatores indicativos do rendimento da porção comestível na carcaça de bovinos. Santa Maria: Universidade Federal de Santa Maria, 1977. 155p. Dissertação (Mestrado em Zootecnia) - Universidade Federal de Santa Maria, 1977.

MÜLLER, L. Normas para avaliação de carcaças e concurso de carcaças de novilhos. Santa Maria: Universidade Federal de Santa Maria, 1987. 31p.

PEROBELLI, Z. V. Estudo das carcaças e da carne de vacas de descarte das raças Charolês e Nelore. Santa Maria: Universidade Federal de Santa Maria, 1993. 70p. Dissertação (Mestrado em Zootecnia) - Universidade Federal de Santa Maria, 1993.

PERON, A.J.; FONTES, C.A.A.; LANA, R.P. et al. Medidas quantitativas e proporções de músculo, tecido adiposo e ossos da carcaça de novilhos de cinco grupos genéticos, submetidos à alimentação restrita e "ad libitum”. Revista da Sociedade Brasileira de Zootecnia, v.24, n.1, p.126-137, 1995.

ROCHA, E.O.; FONTES, C.A.A. Composição corporal, composição do ganho de peso e exigências nutricionais de novilhos de origem leiteira. Revista Brasileira de Zootecnia, v.28, n.1, p.159-168, 1999.

ROCHA, E.O.; FONTES, C.A.A.; PAULINO, M.F. et al. Ganho de peso, eficiência alimentar e características da carcaça de novilhos de origem leiteira. Revista Brasileira de Zootecnia, v.28, n.1, p.148-158, 1999.

STATISTICAL ANALYSIS SYSTEM - SAS. User's guide: Stactistcs. Version 6.11. Cary: 1996.

SIGNORETTI, R.D.; ARAÚJO, G.G.L.; COELHO DA SILVA, J.F. et al. Composição física da carcaça de bezerros da raça holandesa alimentados com dietas contendo diferentes níveis de concentrado. Revista da Soc. Brasileira de Zootecnia, v.28, n.4, p.883-888, 1999.

SILVA, D.J. Análise de alimentos: métodos químicos e biológicos. Viçosa, MG: Universidade Federal Viçosa, 1990. $165 p$.

VÉRAS, A.S.C. Consumo, digestibilidade, composição corporal e exigências nutricionais de bovinos nelore alimentados com rações contendo diferentes níveis de concentrado. Viçosa, MG: Universidade Federal de Viçosa, 2000. 166p. Tese (Doutorado em Zootecnia) - Universidade Federal de Viçosa, 2000. 